*Paper to be presented at the $20^{\text {th }}$ Annual Research Symposium on Monitoring a Comprehensive Nuclear Test Ban Treaty, September 21-23, 1998, at Santa Fe, NM.

\title{
Low-Energy Degassing Mechanisms for a Fluid-Based Radioxenon Detection System
}

\author{
by \\ W. R. Russ, D. O. Stuenkel, and J. D. Valentine \\ Dept. of Mechanical, Industrial and Nuclear Engineering \\ University of Cincinnati \\ P. O. Box 210072 \\ Cincinnati, OH 45221 \\ and
}

K. C. Gross

-

Reactor Analysis Division

Argonne National Laboratory

9700 S. Cass Avenue

Argonne, IL 60439

\begin{abstract}
The submitted manuscript has been created by the University of Chicago as Operator of Argonne National Laboratory ("Argonne") under Contract No. W-31-109-ENG-38 with the U.S. Department of Energy. The U.S. Government retains for itself, and others acting on its behalf, a paid-up, non-exclusive. irrevocable worldwide license in said article to reproduce, prepare derivative works, distribute copies to the public, and perform publicly and display publicly, by or on behalf of the Government.
\end{abstract}

*Work supported by the U. S. Department of Energy, Nuclear Energy Programs under Contract W-31-109-Eng-38

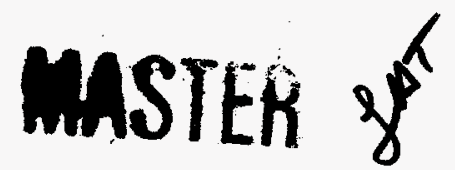




\title{
LOW-ENERGY DEGASSING MECHANISMS FOR A FLUID-BASED RADIOXENON DETECTION SYSTEM
}

\author{
W.R. Russ, D.O. Stuenkel, and J.D. Valentine \\ University of Cincinnati \\ and \\ K.C. Gross \\ Argonne National Laboratory \\ Sponsored in part by U.S. Defense Special Weapons Agency \\ Grant No.: DSWA01-97-1-0027 \\ and in part by \\ U.S. Department of Energy, Environmental Management Science Program \\ Grant No.: DE-FG07-97ER62521
}

\begin{abstract}
A method to concentrate heavy noble gases from the atmosphere using certain organic fluids is being developed. To use this technique in a system to monitor the atmosphere for important noble gas fission products (Xe-131, $\mathrm{Xe}-131 \mathrm{~m}, \mathrm{Xe}-133, \mathrm{Xe}-133 \mathrm{~m}$, and Xe-135) generated by nuclear testing, the radionuclides captured in the fluid must either be detected in the fluid or degassed. This study presents experimental results for a number of possible degassing methods, including heating bubbling with a purge gas, ultrasonic agitation, vacuum, and combinations thereof. Methods were evaluated for energy and time requirements and dilution of the degas product. Initial experiments indicate that in addition to overcoming the standard desorption process dictated by partial pressures per Henry's Law, a capture mechanism must also be overcome to degas. Some type of agitation, thermal or mechanical, can be used to release weakly trapped gas atoms from the fluid, while diffusional mass transfer can be enhanced through entrainment with a purge gas or use of a vacuum. Ultrasonic agitation of a thin film in a strong vacuum has been shown to be the most effective method of those tested. Implementation of an efficient degas system, along with an absorption system and radioxenon detector could result in an ultrasensitive fluidbased radioxenon measurement system that is more portable, less expensive, and simpler than charcoal-based systems which use cryogenic techniques.
\end{abstract}

Keywords: xenon, noble gas, radioxenon, radionuclide 


\section{DISCLAIMER}

This report was prepared as an account of work sponsored by an agency of the United States Government. Neither the United States Government nor any agency thereof, nor any of their employees, make any warranty, express or implied, or assumes any legal liability or responsibility for the accuracy, completeness, or usefulness of any information, apparatus, product, or process disclosed, or represents that its use would not infringe privately owned rights. Reference herein to any specific commercial product, process, or service by trade name, trademark, manufacturer, or otherwise does not necessarily constitute or imply its endorsement, recommendation, or favoring by the United States Government or any agency thereof. The views and opinions of authors expressed herein do not necessarily state or reflect those of the United States Government or any agency thereof. 


\section{DISCLAIMER}

Portions of this document may be illegible in electronic image products. Images are produced from the best available original document. 


\section{OBJECTIVE}

When nuclear weapons are tested underground, radioxenon is one of a few fission products released into the atmosphere that can be detected outside the immediate vicinity of the test. The detection and measurement of elevated levels of ambient radioxenon in the atmosphere can provide corroborative evidence to positively confirm a nuclear detonation or even detect an explosion when other methods are inconclusive. However, the radiation signature of ambient radioxenon cannot typically be discerned from background radiation because of the very low concentrations of ambient radioxenon. Any sensitive radioxenon monitoring system must concentrate ambient radioxenon from large atmospheric samples.

With half-lives on the order of days and limited transport range, ambient radioxenon should be sampled and analyzed in the field. Several ambient radioxenon concentration methods have been used, including molecular sieves [1] and cryogenic charcoal techniques [2]. While these concentration systems are fieldable, a concentration technique that is simpler, cheaper, more portable, and uses less energy and consumables would be more deployable in the field. A new fluid-based concentration system has these characteristics.

In the fluid-based system, heavy noble gases (krypton, xenon, and radon) are preferentially absorbed in an organic fluid and later degassed from the fluid so that the degas product consists of a larger fraction of noble gases and a smaller fraction of other diluting gas. The fluid-based concentration system depends on the development of two constituent sub-systems: the absorption sub-system and the degassing sub-system. The absorption sub-system has already been well developed and characterized [3-5]. However, the degassing sub-system is less well characterized. The objective of this study is to evaluate various degassing techniques and to construct and characterize a degassing sub-system based on these evaluations.

\section{RESEARCH ACCOMPLISHED}

\section{Degassing Theory}

Typical solubility of gases in fluids is described by Henry's Law, where the amount of gas absorbed in a fluid is determined by the type and physical conditions of liquid and gas and the partial pressure of that gas at the interface between the fluid and surrounding atmosphere. Increasing the temperature of a liquid will lower the solubility of any absorbed gas, causing desorption to occur. To induce a change in the amount of absorbed gas, diffusional mass transfer can be driven by a difference in relative concentrations in the fluid and surrounding air. One means of desorbing would be to lower the concentration of gaseous radioxenon above the fluid by drawing a vacuum in the degassing sub-system. Since desorption takes place at the gas-liquid interface, the exchange can be enhanced by increasing the amount of surface area per unit volume of fluid by creating a thin layer of fluid in the degassing sub-system. Bubbling with a purge gas would both increase the surface area per unit volume and enhance diffusional mass transfer by conveying kinetic energy through entrainment. 


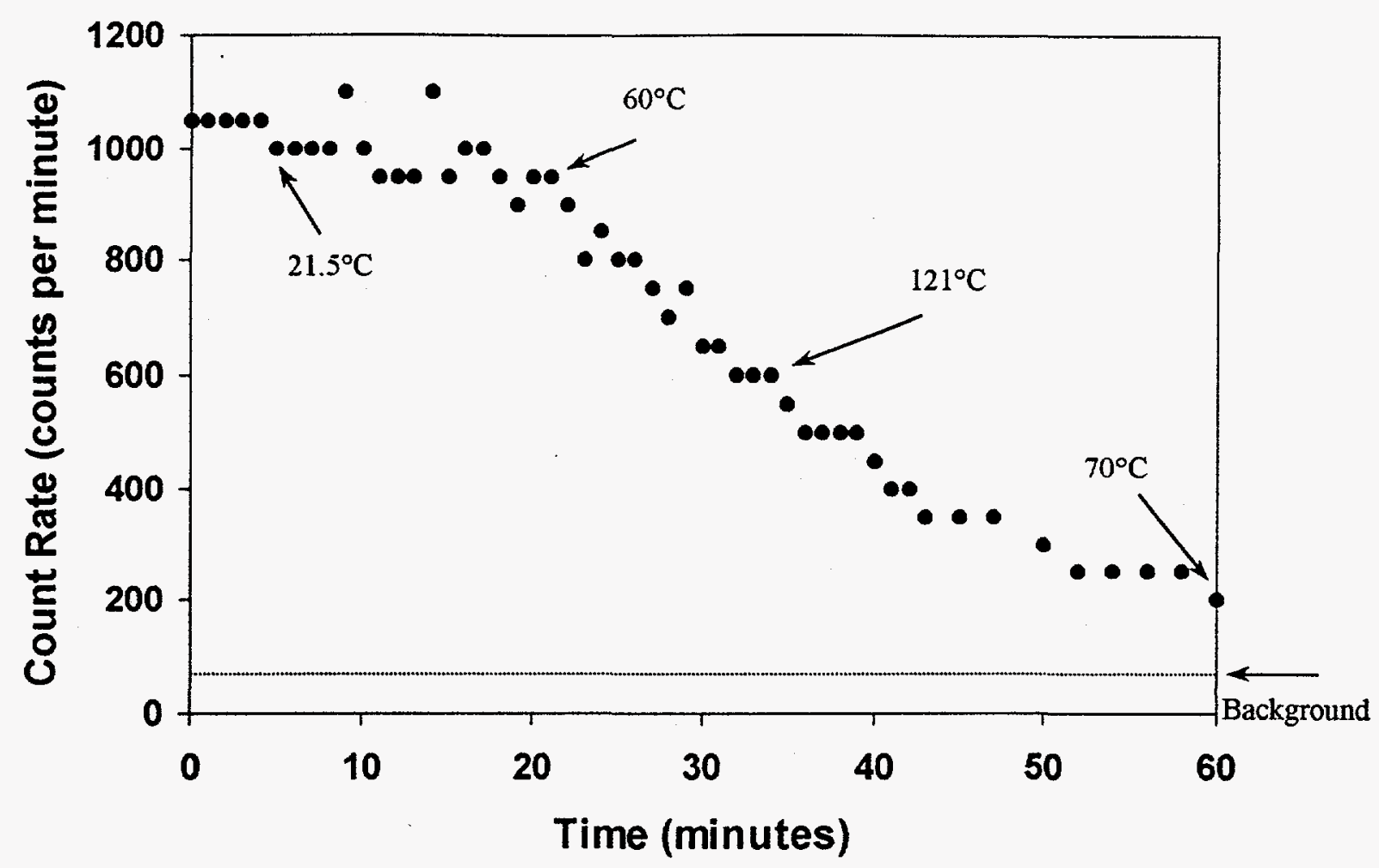

Figure 1 - Time vs. Count Rate for a batch of $200 \mathrm{ml}$ of ${ }^{133} \mathrm{Xe}$ absorbed corn oil in an open beaker being heated on a hot plate. Activity was measured with a Geiger-Mueller counter against the side of the beaker. Temperature in degrees Celsius is indicated intermittently. Background was 100 counts per minute.

However, previous experiments [3] indicate that in addition to a solubility dictated by Henry's Law, some sort of weak capture mechanism specific to heavy noble gases exists to account for the preferential absorption in the organic fluid. Degassing consists not only of enhancing desorption, but also providing a means of overcoming the capture mechanism. Possible methods of overcoming the capture mechanism include thermal and physical agitation.

\section{Evaluation of Degassing Techniques}

The various methods investigated for degassing include heating, bubbling with a purge gas, ultrasonic agitation, vacuum, thin film and synergistic combinations of these methods. The criteria for evaluating various degassing techniques is the efficiency of the method, energy requirements, and amount of inherent dilution. Efficiency indicates the degree to which a given amount of fluid is degassed in a given amount of time. It is desirable to have a technique that can quickly process a large quantity of fluid with a $100 \%$ degas. Additionally, for a system deployed in the field, energy requirements and consumables should minimized. Finally, the purpose of the concentration system would be defeated if the degas product were to be diluted with other gases, such as air.

The advantage of heating as a method of degassing is that increased thermal agitation both overcomes the capture mechanisin and enhances desorption by lowering the solubility of gas in the fluid. Testing the ability of heat 


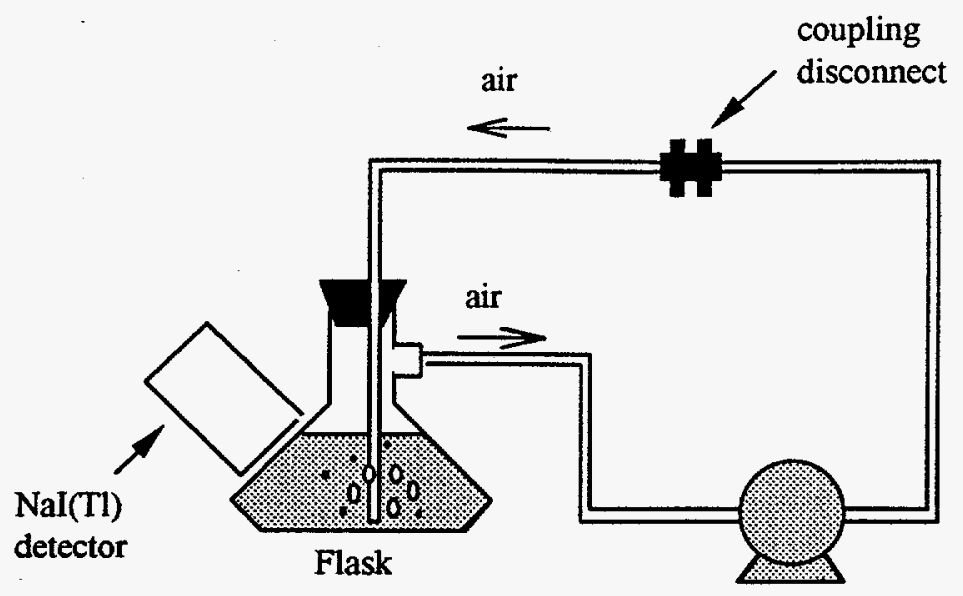

Figure 2 - Diagram of the experimental setup used to explore the use of bubbling alone to degas the oil. Initially, the coupling was connected, and then it was taken apart to allow fresh air into the loop.

to degas was done with a $250 \mathrm{ml}$ open beaker placed on a hot plate. The beaker was filled with $200 \mathrm{ml}$ of corn oil previously saturated with ${ }^{133} \mathrm{Xe}$ in an absorption sub-system. A thermometer was used to measure the temperature of the fluid. A Geiger-Mueller counter placed against the side of the beaker measured the activity remaining in the oil over time at various temperatures, as shown in Figure 1. The results indicate a threshold temperature of about $60^{\circ} \mathrm{C}$, below which no appreciable degassing occurred. Between $60^{\circ} \mathrm{C}$ and $121^{\circ} \mathrm{C}$, the degas rate was relatively constant and appears to be independent of temperature. A complete degas of $200 \mathrm{ml}$ of oil required about 1 hour with heating alone.

Bubbling with a purge gas has the advantage of increasing the effective surface area of the exchange interface, imparting kinetic energy by entrainment to enhance mass transfer out of the fluid, and causing mechanical agitation, thereby overcoming the capture mechanism. Figure 2 illustrates the bubbling experiment using $200 \mathrm{ml}$ of corn oil, saturated with ${ }^{133} \mathrm{Xe}$ in a $250 \mathrm{ml}$ flask with a $\mathrm{NaI}(\mathrm{Tl})$ detector against the side of the flask to measure activity of radioxenon in the oil. Air was circulated via an air pump and a coupling disconnect. Initially, the pump was started to commence bubbling with the coupling intact. As shown in Figure 3, there was a rapid degas that soon tapered off and saturated. The sample could not be degassed completely because the partial pressure of the xenon gas above the sample reached equilibrium with the gas still in solution. The coupling was then disconnected so that fresh air was used to purge the sample. This resulted in the rapid degassing of the remainder of the xenon in the oil. It is apparent that only fresh air, not recirculated air, is effective in degassing the fluid completely.

Another method investigated was ultrasonic agitation. Since absorption is in some part a result of a capture mechanism, one possibility for efficiently breaking such a bond would be to use ultrasonic agitation. A batch of 100 $\mathrm{ml}$ of oil, containing absorbed ${ }^{133} \mathrm{Xe}$, was placed in a beaker, along with a thermometer. An ultrasonic disrupter was submerged about $3 \mathrm{~cm}$ into the oil and vibrated at a frequency of $20 \mathrm{kHz}$. A NaI(Tl) detector measured the ${ }^{133} \mathrm{Xe}$ 


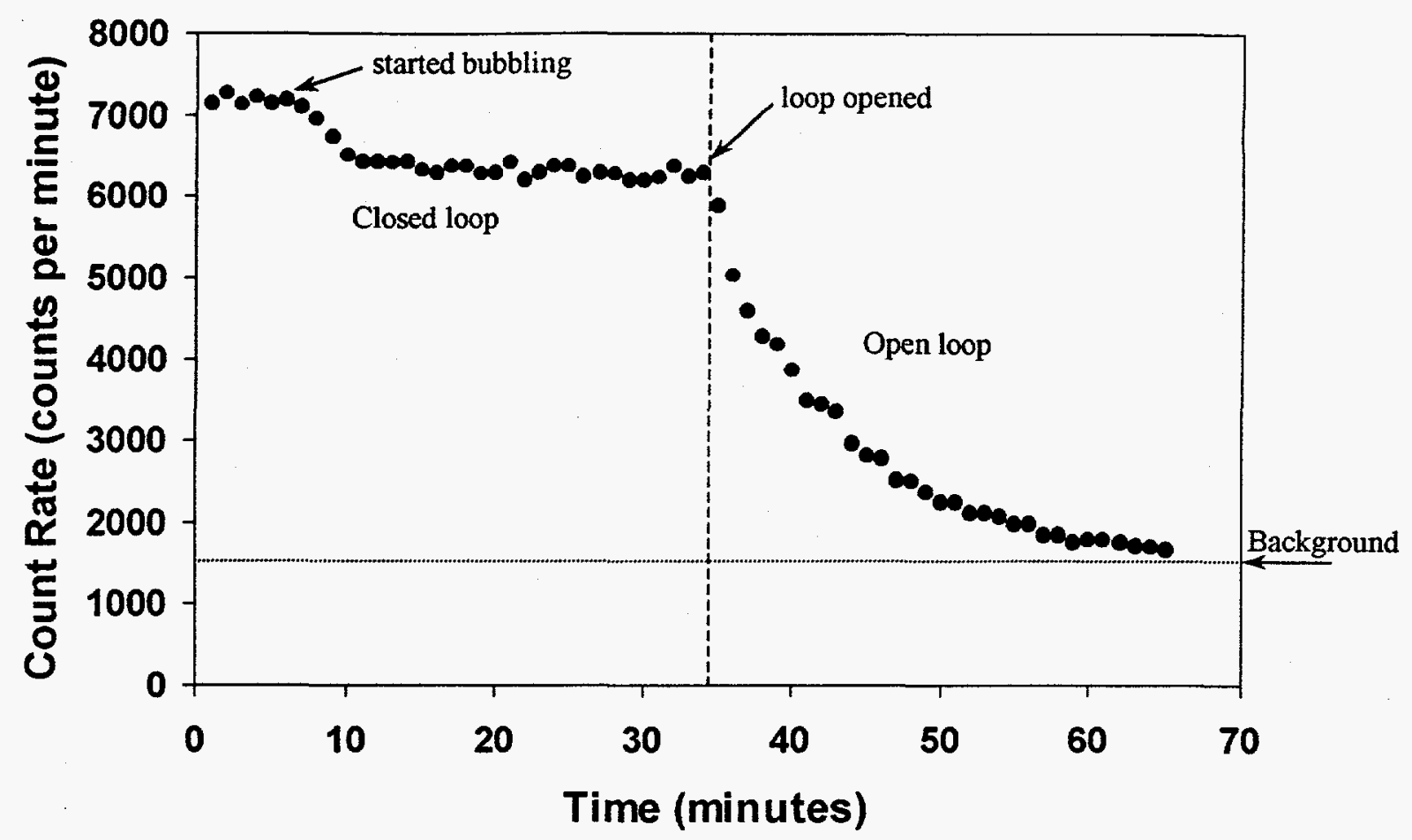

Figure 3 - Time vs. Count Rate for a batch of $200 \mathrm{ml}$ of ${ }^{133} \mathrm{Xe}$ absorbed corn oil in a closed flask using an air pump to bubble air first as a closed loop and then opened loop, venting to the exhaust hood. Activity was measured with a $2^{\prime \prime} \times 2^{\prime \prime} \mathrm{NaI}(\mathrm{Tl})$ detector in multichannel scaler mode $(1 \mathrm{~min}$. dwell) against the side of the flask. Background was 1650 counts per minute.

activity of the oil over time while the temperature was also monitored to assess any thermar effects. A slow, stable degas rate was evident, as shown in Figure 4.

A vacuum was tested to measure its ability to degas. A strong vacuum could create a large gradient in the partial pressure resulting in a significant driving force for desorption. While effectively driving desorption, a vacuum by itself may not be sufficient to overcome the capture mechanism. A vacuum may work best combined with some form of agitation, preferably cavitating. To test the effects of a vacuum and mechanical agitation, a vacuum chamber was constructed of acrylic containing a magnetic stirrer. The ${ }^{133} \mathrm{Xe}$ activity in $300 \mathrm{ml}$ of ${ }^{133} \mathrm{Xe}$ absorbed oil was again measured by a $\mathrm{NaI}(\mathrm{Tl})$ detector. A vacuum of $720 \mathrm{~mm} \mathrm{Hg}$ was applied and did little to degas without the aid of the cavitating magnetic stirrer, as shown in Figure 5. The combination of the magnetic stirrer and vacuum provided an efficient means to degas. Further experiments demonstrated that the magnetic stirrer also failed to degas without the aid of a strong vacuum. The concept of using a thin layer to enhance the degas was also tested by repeating the experiment with both $150 \mathrm{ml}$ and $600 \mathrm{ml}$ of oil. These different volumes in the same chamber resulted in different ratios of surface area to volume. The greater surface area to volume sample degassed more quickly and completely. 


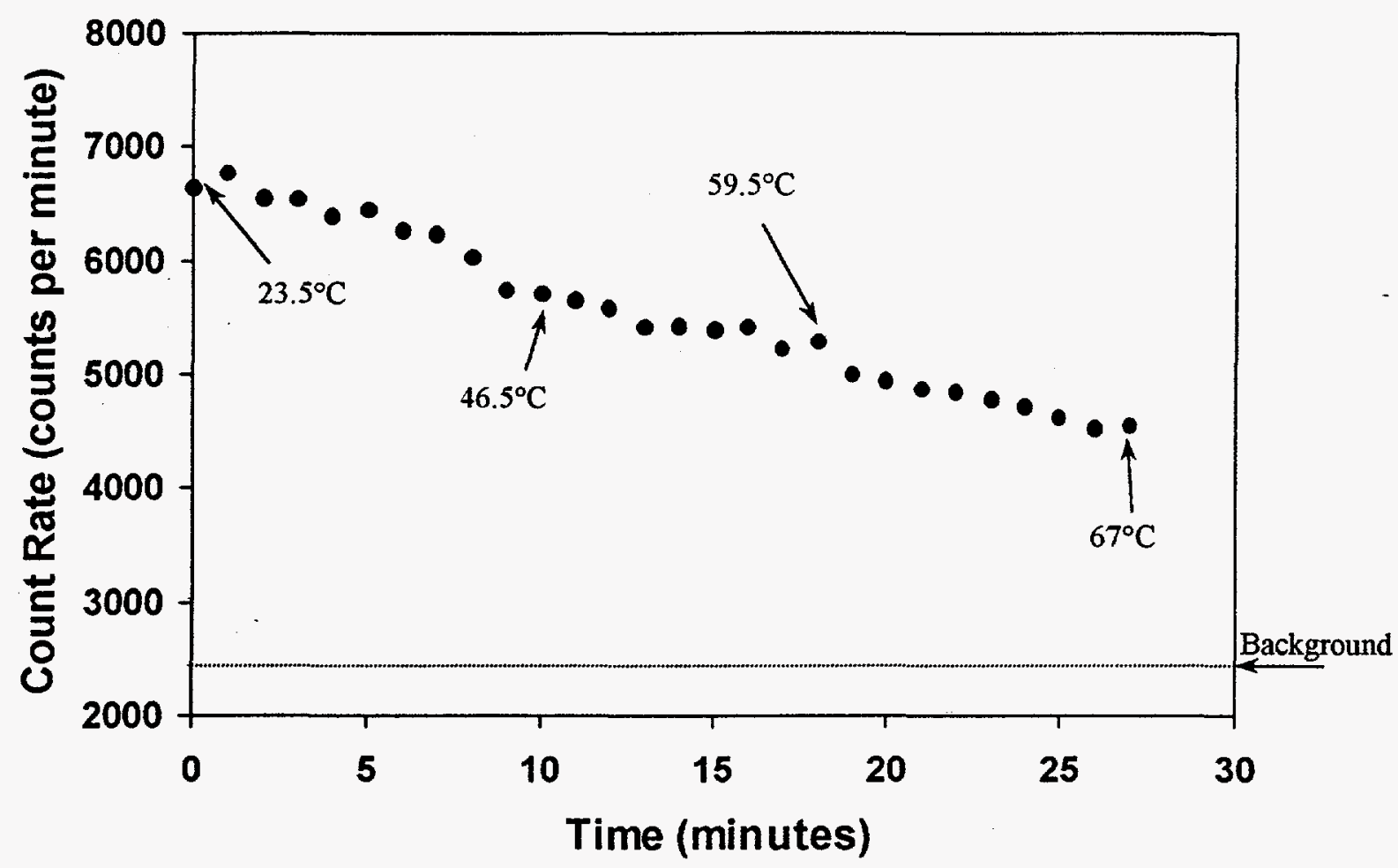

Figure 4 - Time vs. Count Rate for a batch of $100 \mathrm{ml}$ of ${ }^{133} \mathrm{Xe}$ absorbed corn oil in an open beaker being sonically agitated with setting 4 . Activity was measured with a $2^{\prime \prime} \times 2^{\prime \prime} \mathrm{NaI}(\mathrm{Tl})$ detector against the side of the beaker in multichannel scaler mode $(1 \mathrm{~min}$. dwell). Temperature in degrees Celsius is indicated intermittently, with heating caused by sonic agitation alone. Background was 2450 counts per minute.

Design and Characterization of a Degassing Sub-System

Heating, while effective, does not degas quickly enough and also requires considerable energy both for the initial heating and subsequent cooling to reuse the oil for effective absorption. Bubbling with a purge gas was only effective with fresh air which would cause dilution of the degas product. Ultrasonic agitation alone was inefficient, but might be considered for use with other techniques. A strong vacuum was shown to be an efficient means to degas when combined with cavitating agitation. Degassing the oil while in the form of a thin layer or film was shown to enhance degassing. These results indicate that a thin film of fluid ultrasonically agitated into cavitation while in a strong vacuum would be an effective, efficient degassing method. Incorporating these characteristics resulted in a degassing sub-system as shown in Figure 6. This degassing chamber consists of a polycarbonate continuous flow cell, which continuously directs oil onto the tip of a sonic disrupter while in a strong vacuum. While still in the vacuum, the flowing oil then drains down a thin-film tower, which consists of a packed bed of beads to increase the oil surface area to volume ratio. In characterizing this degassing sub-system, a batch of $200 \mathrm{ml}$ of oil, saturated ${ }^{133} \mathrm{Xe}$ was degassed at a flow rate of 0.1 liters per minute, with a degas of $67 \%$ after a single pass. 


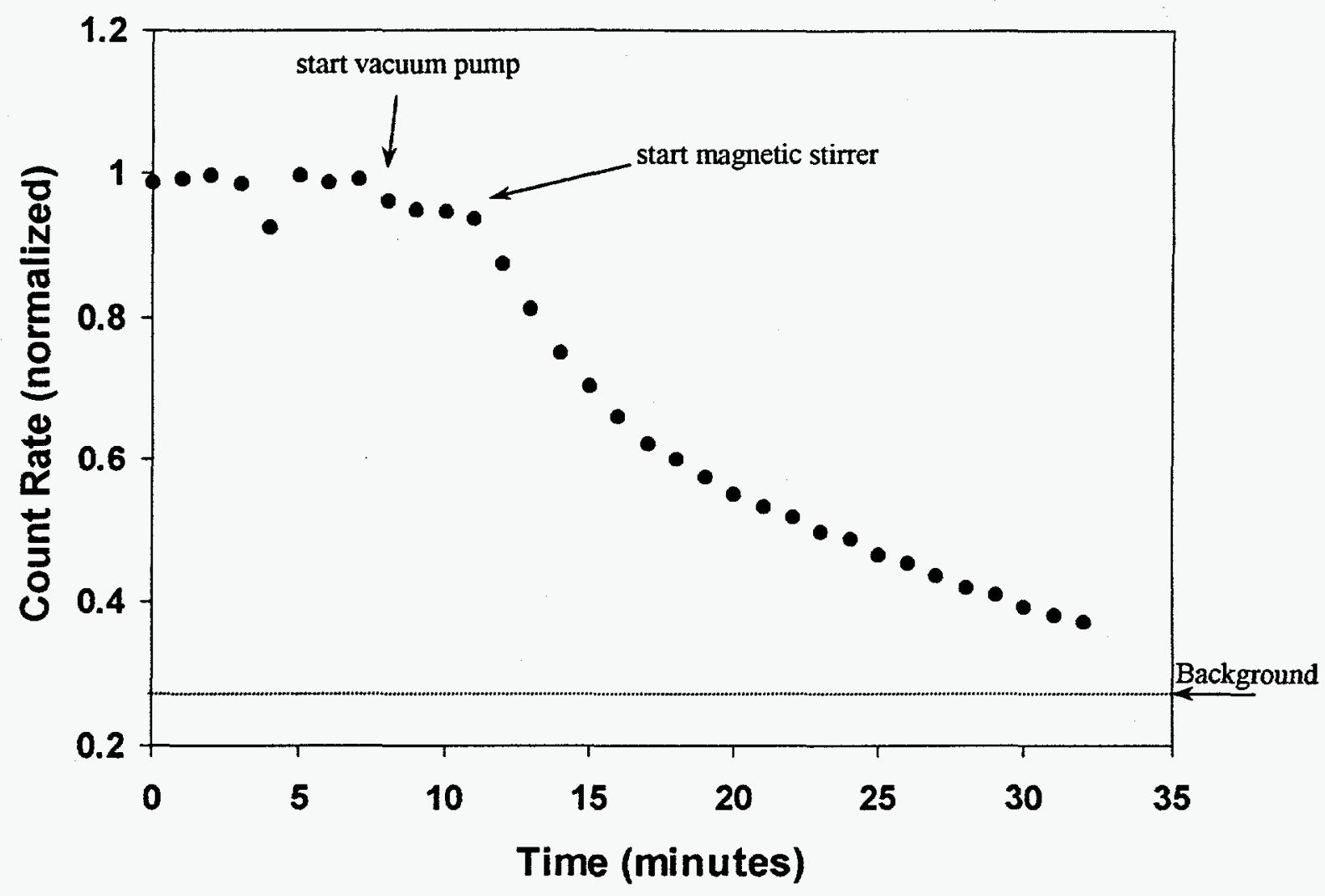

Figure 5 - Time vs. Count Rate for a batch of $300 \mathrm{ml}$ of ${ }^{133} \mathrm{Xe}$ absorbed corn oil in a vacuum chamber with a magnetic stirrer. Activity was measured with a $2^{\prime \prime} \times 2^{\prime \prime} \mathrm{NaI}(\mathrm{Tl})$ detector in multchannel scaler mode (1 min. dwell) against the side of the chamber. Vacuum of 28.4 " $\mathrm{Hg}$. Background was 0.28 with count rate normalized.

\section{CONCLUSIONS AND RECOMMENDATIONS}

The evaluations of the degassing techniques have indicated that agitating a thin film of fluid in a strong vacuum would be a composite degassing method with good efficiency, low energy requirements and little or no dilution of the degas. Constructing and characterizing a degassing sub-system based on this evaluation has resulted in a component that continuously degasses fluid in an efficient manner. Recommendations include refining the means of agitating a thin film in a vacuum and scaling the degassing sub-system up to accommodate greater flow rates. Finally, further studies should integrate the degassing sub-system with the absorption sub-system, in order to characterize the concentration system as a whole. 


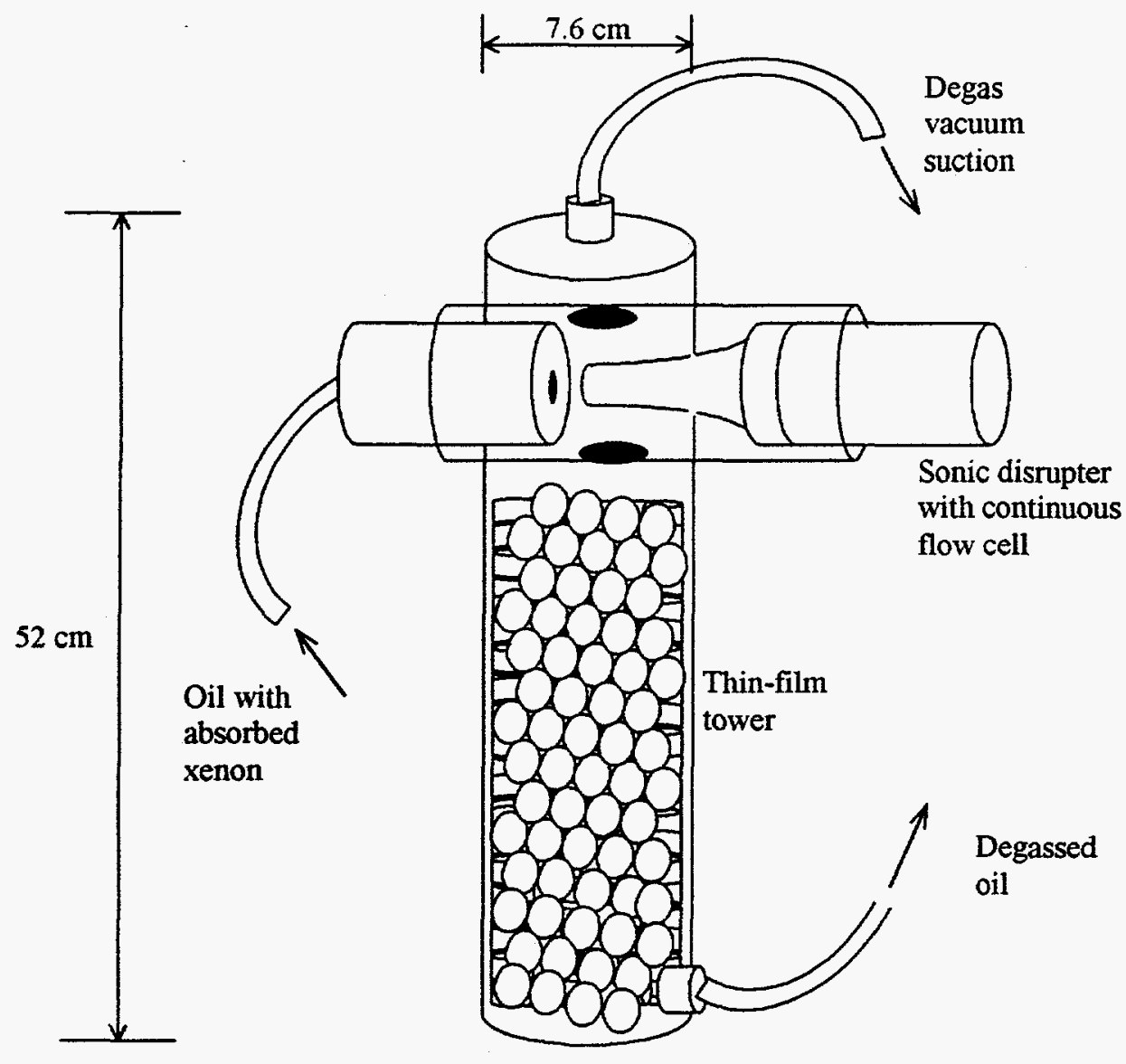

Figure 6 - Diagram of the degassing chamber constructed as a combination of sonic agitation with strong vacuum and thin-film tower with a strong vacuum.

\section{REFERENCES}

[1] W. R. Schell, M. J. Tobin, D. J. Marsan, C. W. Schell, J. Vives-Batlle, and S. R. Yoon, "Measurement of Fission Product Gases in the Atmosphere," Nuclear Instruments and Methods in Physics Research (Section A) 385 (1997) 277-284, Elsevier Science, Ansterdam, Netherlands 1997.

[2] T. W. Bowyer, K. H. Abel, W. K. Hensley, C. W. Hubbard, A. D. McKinnon, M. E. Panisko, R. W. Perkins, P. L. Reeder, R. C. Thompson, and R. A. Warner, "Automatic Radioxenon Analyzer for CTBT Monitoring," PNNL-11424 UC-713, December, 1996.

[3] M. Steinberg and B. Manowitz, "An Absorption Process for Recovery of Fission Product Noble Gases," BNL 493 (T-115), Feb. 1958.

[4] K. V. Liu, J. D. Gabor, K. C. Gross, and R. E. Holtz, "Fluid-Based Radon Mitigation Technology Development for Decontamination and Decomissioning," Proceedings of the Fourth International Conference on Nuclear Engineering, New Orleans, Louisiana, 10-14 March 1996.

[5] B. Rooney, K. Gross, R. Nietert, J. Valentine, and W. Russ, "A Fluid-Based Measurement System for Airborne Radioxenon Surveillance," Proceedings of the $19^{\text {th }}$ Annual Seismic Research Symposium on Monitoring a Comprehensive Test Ban Treaty, 23-25 September 1997. 